\title{
Bakterien lieben Glukose
}

\section{Ein 44-jähriger Mann mit lange be-} stehendem Diabetes mellitus Typ 2 suchte wegen seit vier Tagen bestehendem Fieber und Bauchschmerzen das Krankenhaus auf. Seine Herzfrequenz betrug 137/min, der Blutdruck $81 / 44 \mathrm{~mm} \mathrm{Hg}$ und er wies einen Druckschmerz, jedoch keine Abwehrspannung im Bereich des rechten oberen Quadranten auf.

- Im Röntgen-Thorax stellte sich im rechten Oberbauch eine ausgedehnte kugelförmige Verdichtungsfigur dar (Abb. A, Pfeilspitzen). Computertomografisch erwies sich dieser Befund als ausgedehnter Leberabszess, der Gas und Flüssigkeit enthielt (Abb. B, Pfeilspitzen). Unter der Verdachtsdiagnose eines pyogenen Leberabszesses und dem Nachweis von Klebsiella pneumoniae in

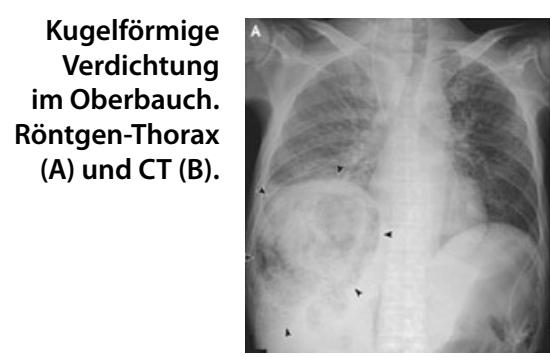

der Blutkultur wurde der Patient antibiotisch behandelt. Sein Zustand verschlechterte sich allerdings rapide und er starb innerhalb von 48 Stunden nach Aufnahme.

\section{Kommentar}

Die Kombination aus allgemeiner Überzuckerung der Gewebe und einem bei vielen Diabetikern vorhandenen Immundefekt erhöht das Risiko für Abszesse bei Diabetes mellitus ganz allgemein. Abszesse sind auf-

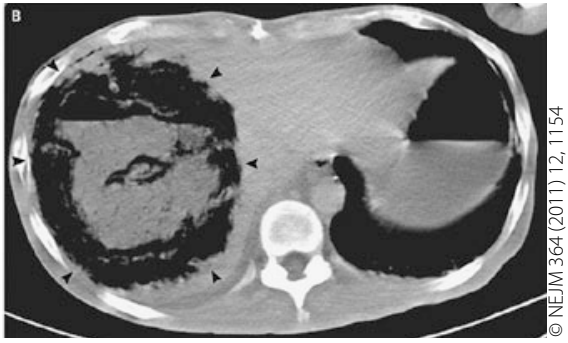

grund der ungünstigen Gefäßversorgung einer Antibiotikatherapie oft nicht gut zugänglich. Hätte man den Patienten operiert, wäre der Verlauf sicher nicht so foudroyant gewesen. Fieber und Bauchschmerzen sind bei Diabetikern ernster zu nehmen als bei Stoffwechselgesunden.

H. S. FÜESSL =

- Chin-Wie Yu, Chin-Hsing Lee

(Chang Gung Memorial Hospital, Taoyuan, Taiwan): Pyogenic liver abscess. New Engl. J. Med. 364 (2011) 12, 1154 